\title{
PEMBERDAYAAN MAHASISWA FAKULTAS TEKNIK DENGAN PROGRAM KREATIFITAS MAHASISWA (PKM)
}

\author{
Lusi Dwi Putri*1, Repi ${ }^{2}$, Fitridawati Soehardi ${ }^{3}$ \\ ${ }^{1,3}$ Program Studi Teknik Sipil, Fakultas Teknik, Universitas Lancang Kuning \\ ${ }^{2}$ Program Studi Arsitektur, Fakultas Teknik, Universitas Lancang Kuning \\ *E-mail: lusidwiputri@unilak.ac.id
}

\begin{abstract}
This Student Creativity Program (PKM) is not yet effective as an annual culture of Unilak Faculty of Engineering (FT) students every year. In 2016 there were 15 (fifteen) proposals, but no one had passed yet and in 2017 there were no proposals. The stages of the implementation of activities were in the form of program socialization, excursion and mentoring studies. The target to be achieved is that students understand what the PKM program is and the outcomes to be achieved are student empowerment services, scientific reports and articles as well as the output of the program as program outcomes, namely PKM proposals. PKM is carried out by 41 FT student names, and all have registered for the 2017 PKM funding program in 2018. On April 3, 2018, Unilak passed 3 PKM proposals and one of them was from FT-Unilak. The interest of FT students is still dominant in the PKM-P scheme, which is equal to $64.29 \%$, the proposed PKM-K scheme is $28.57 \%$, the PKM-M scheme is only $7.14 \%$. The conclusion obtained was the increasing capacity of FT students in understanding the PKM program and being able to prepare proposals submitted to the Director General of Belmawa Kemenristekdikti.
\end{abstract}

Keywords-Creativity,Sstudents, Empowerment, PKM Proposals.

\begin{abstract}
Abstrak
Program Kreatifitas Mahasiswa (PKM) ini belum efektif menjadi budaya tahunan mahasiswa Fakultas Teknik (FT) Unilak di setiap tahunnya. Tahun 2016 ada 15 (lima belas) usulan, namun belum ada yang lolos serta di tahun 2017 belum ada usulan. Tahapan pelaksanaan kegiatan berupa sosialisasi program, studi ekskursi dan pendampingan. Target yang ingin dicapai adalah mahasiswa memahami apa itu program PKM dan luaran yang ingin dicapai adalah jasa pemberdayaan mahasiswa, laporan dan artikel ilmiah serta output kegiatan sebagai outcome program yaitu proposal PKM. Hasil yang diperoleh adalah mahasiswa memahami apa itu program PKM sehingga mampu menghasilkan 14 proposal PKM yang diusung oleh 41 nama mahasiswa FT, dan semuanya sudah mendaftar pada program PKM tahun 2017 pendanaan tahun 2018. Tanggal 3 April 2018, Unilak lolos 3 proposal PKM dan salah satunya dari FT-Unilak. Minat mahasiswa FT masih dominan skim PKM-P yaitu sebesar 64,29\%, skim PKM-K yang diajukan sebesar 28,57\%, skim PKM-M hanya 7,14\%. Kesimpulan yang diperoleh adalah meningkatnya kapasitas mahasiswa FT dalam memahami program PKM dan mampu menyusun proposal yang diajukan ke Dirjen Belmawa Kemenristekdikti.
\end{abstract}

Kata Kunci-Kreativitas, Mahasiswa, Pemberdayaan, Proposal PKM.

\section{PENDAHULUAN}

Lulusan Perguruan tinggi dituntut untuk memiliki academic knowledge, skill of thinking, management skill dan communication skill. Kekurangan atas salah satu dari keempat keterampilan/kemahiran tersebut dapat menyebabkan berkurangnya mutu lulusan. Sinergisme akan tercermin melalui kemampuan lulusan dalam kecepatan menemukan solusi atas persoalan yang dihadapinya. Agar mahasiswa dapat mencapai level tersebut, maka agar optimal diupayakan dalam sebuah kegiatan yang diberi nama Program Kreativitas Mahasiswa. (Pedoman PKM 2017, Direktorat Kemahasiswaan Dirjen Belmawa Kemenristekdikti). 
Program Kreativitas Mahasiswa (PKM) dilaksanakan pertama kali pada tahun 2001, yaitu setelah dilaksanakannya program restrukturisasi di lingkungan Ditlitabmas. Kegiatan pendidikan, penelitian dan pengabdian kepada masyarakat yang selama ini sarat dengan partisipasi aktif mahasiswa, diintegrasikan ke dalam satu wahana yaitu PKM. Pada gambar 1 dapat dilihat perolehan PKM tahun 2017 secara nasional, Provinsi Riau diwakili oleh Universitas Riau di peringkat 10 dengan jumlah proposal 92 proposal.

Perolehan PKM secara Nasional untuk proposal tahun 2016 pendanaan tahun 2017, peringkat PT yang didanai di Provinsi Riau dapat dilihat pada Tabel 1. Universitas Lancang Kuning pada peringkat ke- 6 dengan proposal yang didanai sebanyak 2 proposal yaitu proposal mahasiswa dari Fakultas Pertanian dan Fakultas Ilmu Budaya.

Tahun 2015 Fakultas Teknik mengusulkan 1 (satu) proposal PKM dan lolos didanai sekaligus sebelumnya adalah pemenang lomba karya tulis yang diselenggarakan Kopertis Wilayah X. Pada tahun 2016 angka tersebut mulai naik menjadi 15 proposal mahasiswa namun belum ada yang lolos didanai. Setahun berikutnya yaitu pada tahun 2017 belum ada proposal mahasiswa yang diajukan untuk PKM. Hal ini mengindikasikan bahwa kurangnya minat mahasiswa Fakultas Teknik dalam mengikuti PKM. Disamping itu, selain kurangnya minat mahasiswa Fakultas Teknik terhadap PKM, ternyata masih banyak ditemui mahasiswa yang belum mengetahui apa itu PKM, sementara PKM ini terdiri dari 7 bidang unggulan yang bias diikuti oleh mahasiswa antara lain; PKM Penelitian (PKM-P), PKM Pengabdian Masyarakat (PKM-M), PKM Kewirausahaan (PKM-K), PKM_Penerapan Teknologi (PKM-T), PKM Karsa Cipta (PKM-KC), PKM Gagasan Tertulis (PKM-GT) dan PKM Artikel Ilmiah (PKM-AI).

Dengan kondisi informasi yang tidak massif di Fakultas Teknik tentang PKM mengakibatkan program ini tidak menarik minat mahasiswa ditambah lagi dengan kondisi kurangnya minat mereka itu sendiri untuk kegiatan yang tidak bersentuhan langsung dengan mata kuliah yang mereka ambil. Hal ini pernah dicoba pada periode sebelumnya terkait program kemahasiswaan lainnya yang dimiliki oleh Dirjen Belmawa seperti Program Hibah Bina Desa (PHBD). Dari seluruh mahasiswa Fakultas Teknik hanya 2 proposal yang diajukan ke Dikti, dan hanya 1 proposal yang lolos di eleksi tahap 1 namun belum lolos di seleksi selanjutnya.

\section{METODE}

Metode pelaksanaan yang digunakan dalam kegiatan IbM ini adalah sebagai berikut :

\subsection{Tahapan Kegiatan}

1. Kegiatan belajar di kelas, dengan materi pembelajaran yaitu :

Tabel 1. Materi Pembelajaran di Kelas

\begin{tabular}{|c|c|}
\hline Kegiatan Belajar 1 & Sosialisasi PKM \\
\hline Tujuan & Peserta memahami ruang lingkup PKM \\
\hline $\begin{array}{l}\text { Materi atau ringkasan } \\
\text { belajar }\end{array}$ & $\begin{array}{l}\text { Peserta akan diajak untuk mendikusikan beberapa hal yaitu } \\
\text { - Tujuan PKM } \\
\text { - Karakteristik Umum bidang PKM } \\
\text { - Alur Kegiatan PKM } \\
\text { - Tahapan Kegiatan PKM }\end{array}$ \\
\hline Perlengkapan & $\begin{array}{l}\text { - Laptop dan Infocus } \\
\text { - Kertas plano } \\
\text { - Papan tulis / white board dgn perlengkapannya } \\
\text { - Spidol, selotip kertas dan jepitan besar }\end{array}$ \\
\hline
\end{tabular}


DINAMISIA - Jurnal Pengabdian Kepada Masyarakat Vol. 2, No. 2 Desember 2018, Hal. 315-321

\section{Kegiatan Belajar $2 \quad$ Penjelasan Bidang PKM}

\begin{tabular}{|c|c|}
\hline Tujuan & Peserta memahami bidang-bidang PKM \\
\hline $\begin{array}{c}\text { Materi atau ringkasan } \\
\text { belajar }\end{array}$ & $\begin{array}{l}\text { Peserta akan diajak untuk mendikusikan beberapa hal tentang } \\
\text { bidang-bidang PKM yaitu : } \\
\text { - PKM Penelitian (PKM-P) } \\
\text { - PKM Pengabdian Masyarakat (PKM-M) } \\
\text { - PKM Kewirausahaan (PKM-K) } \\
\text { - PKM_Penerapan Teknologi (PKM-T) } \\
\text { - PKM Karsa Cipta (PKM-KC) } \\
\text { - PKM Gagasan Tertulis (PKM-GT) } \\
\text { - PKM Artikel Ilmiah (PKM-AI) }\end{array}$ \\
\hline Perlengkapan & $\begin{array}{l}\text { - Laptop dan Infocus } \\
\text { - Kertas plano } \\
\text { - Papan tulis / white board dgn perlengkapannya } \\
\text { - Spidol, selotip kertas dan jepitan besar }\end{array}$ \\
\hline
\end{tabular}

2. Studi Ekskursi

\begin{tabular}{|c|c|c|c|}
\hline No & Studi Ekskursi & Tujuan & Lokasi \\
\hline 1 & $\begin{array}{c}\text { Kawasan } \\
\text { permukiman } \\
\text { kumuh Kota } \\
\text { Pekanbaru }\end{array}$ & $\begin{array}{l}\text { Mahasiswa memahami segala } \\
\text { potensi yang dimiliki } \\
\text { masyarakat serta kendala yang } \\
\text { dimiliki, untuk } \\
\text { mengembangkan kemampuan } \\
\text { berpikir dan berkomunikasi }\end{array}$ & $\begin{array}{l}\text { Wilayah kumuh } \\
\text { Kota Pekanbaru }\end{array}$ \\
\hline 2 & $\begin{array}{l}\text { Sarana dan } \\
\text { Prasarana } \\
\text { Infrastruktur } \\
\text { Perkotaan }\end{array}$ & $\begin{array}{c}\text { Mahasiswa memahami fungsi } \\
\text { sarana dan prasarana } \\
\text { infrastruktur yang ada di } \\
\text { perkotaan }\end{array}$ & Kota Pekanbaru \\
\hline 3 & $\begin{array}{l}\text { Kawasan wisata } \\
\text { sejarah }\end{array}$ & $\begin{array}{c}\text { Meningkatkan kemampuan } \\
\text { akademik sekaligus } \\
\text { kemampuan manajemen } \\
\text { mahasiswa }\end{array}$ & $\begin{array}{c}\text { Kawasan wisata } \\
\text { sejarah }\end{array}$ \\
\hline
\end{tabular}

3. Pendampingan proposal PKM, melalui pelatihan dan pendampingan berkelanjutan. Tim pengusul bisa menjadi dosen pendamping PKM mahasiswa dengan catatan memang ditunjuk oleh tim mahasiswa yang megusulkan proposal PKM tersebut.

\subsection{Metode Pembelajaran}

Metode pendekatan yang digunakan dalam pembelajaran adalah sebagai berikut :

1. Ceramah dan Diskusi

Substansi yang disampaikan adalah Sosialisasi PKM berikut penjelasan bidang PKM.

2. Studi Ekskursi

Kunjungan ke Kawasan permukiman kumuh Kota Pekanbaru, Sarana dan Prasarana

Infrastruktur Perkotaan dan kawasan wisata sejarah.

3. On The Job Training (OJT)/Praktik

Metode praktik ini digunakan dengan tujuan akhir mahasiswa mampu membuat proposal

PKM sesuai dengan panduan PKM tahun 2017. 


\subsection{Monev Pelaksanaan dan Keberlanjutan}

Monev pelaksanaan dan keberlanjutan merupakan suatu sistem yang digunakan setelah selesai pelaksanaan kegiatan pengabdian. Bentuk monev tersebut adalah sebagai berikut :

1. Evaluasi hasil kuisioner mahasiswa mengenai pemahaman mereka terhadap PKM.

2. Evaluasi pelaksanaan studi ekskursi

Untuk mengetahui kemampuan mahasiswa dalam berpikir dan bertindak kreatif terkait informasi yang mereka peroleh selama di lapangan.

3. Pendampingan penyusunan proposal PKM

4. Keberlanjutan (menjadikan PKM membudaya di Fakultas Teknik)

\section{HASIL DAN PEMBAHASAN}

Hasil yang diperoleh dari kegiatan PKM ini diuraikan sebagai berikut :

\section{Tempat Pelatihan}

Kegiatan IbM dilaksanakan di kampus Fakultas Teknik Unilak dan beberapa kunjungan lapangan ke beberapa kelurahan di Kota Pekanbaru (kelurahan Sri Meranti, kelurahan Lembah Damai, kelurahan Rintis, kelurahan Kampung Bandar).

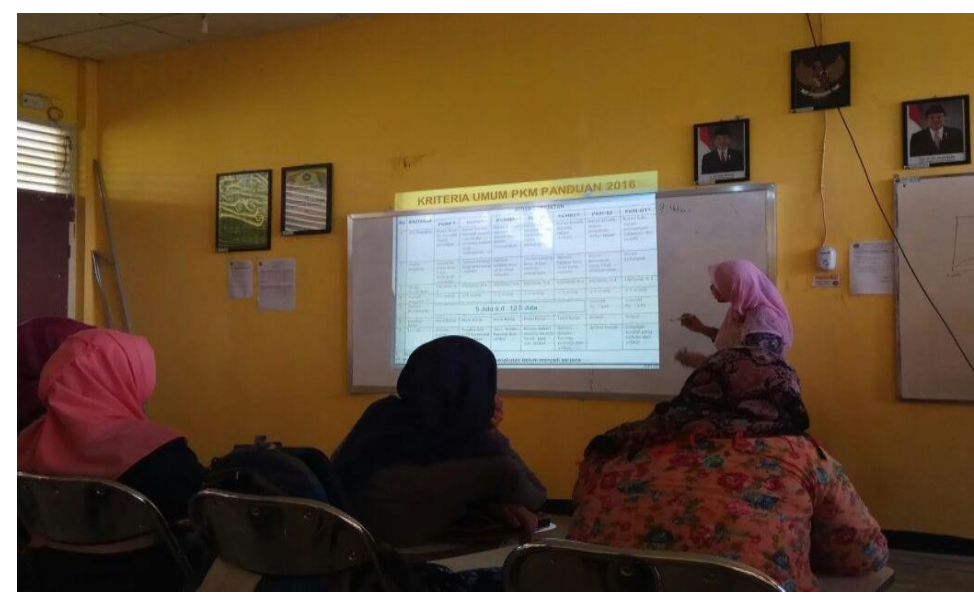

Gambar 1. Sosialisasi Panduan PKM di Fakultas Teknik Unilak

\section{Peserta Kegiatan IbM}

Peserta kegiatan berjumlah 41 (empat puluh satu) orang mahaiswa/i yang berasal dari anggota himpunan mahasiswa fakultas Teknik.

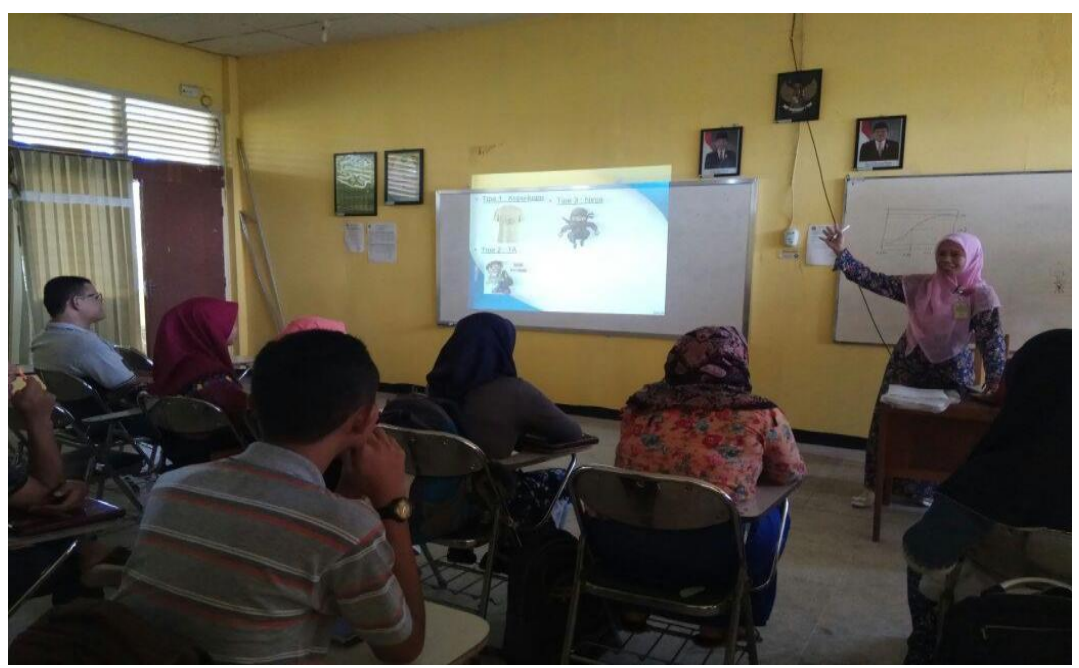

Gambar 2. Peningkatan Motivasi Mahasiswa Fakultas Teknik Unilak 


\section{Hasil Kegiatan IbM} tabel berikut :

Hasil akhir pelatihan dari semua peserta serta skim PKM yang diminati dapat dilihat pada

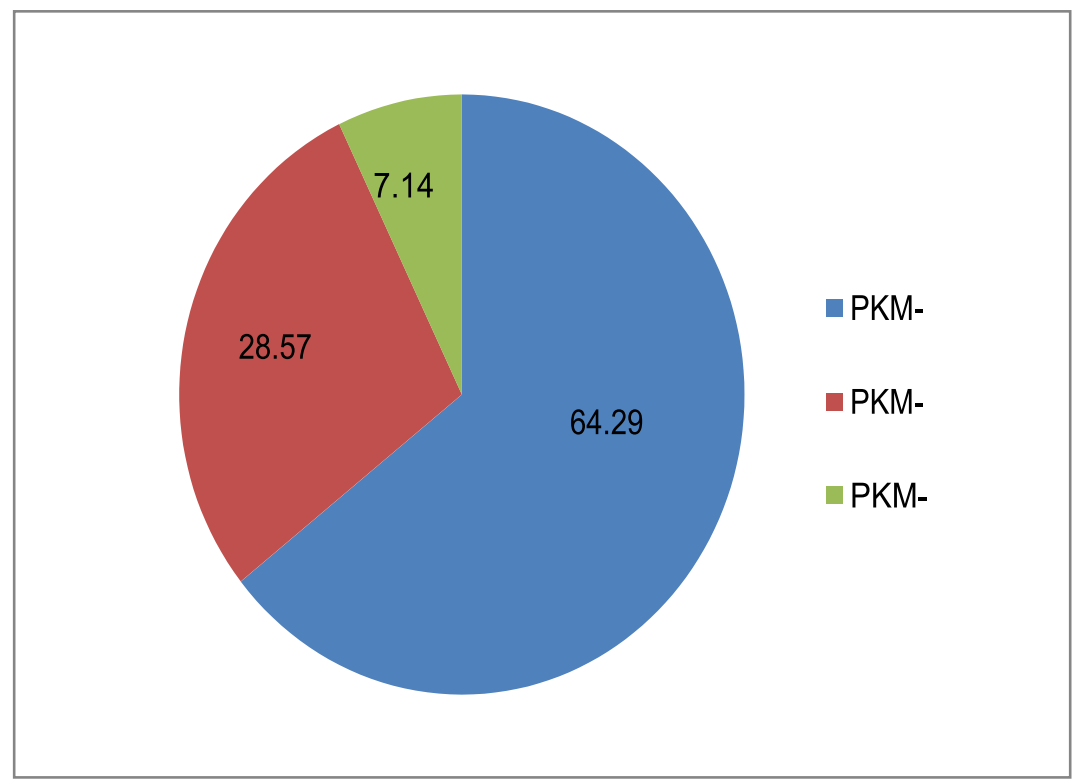

Gambar 3. Peminatan Mahasiswa FT kepada skim PKM

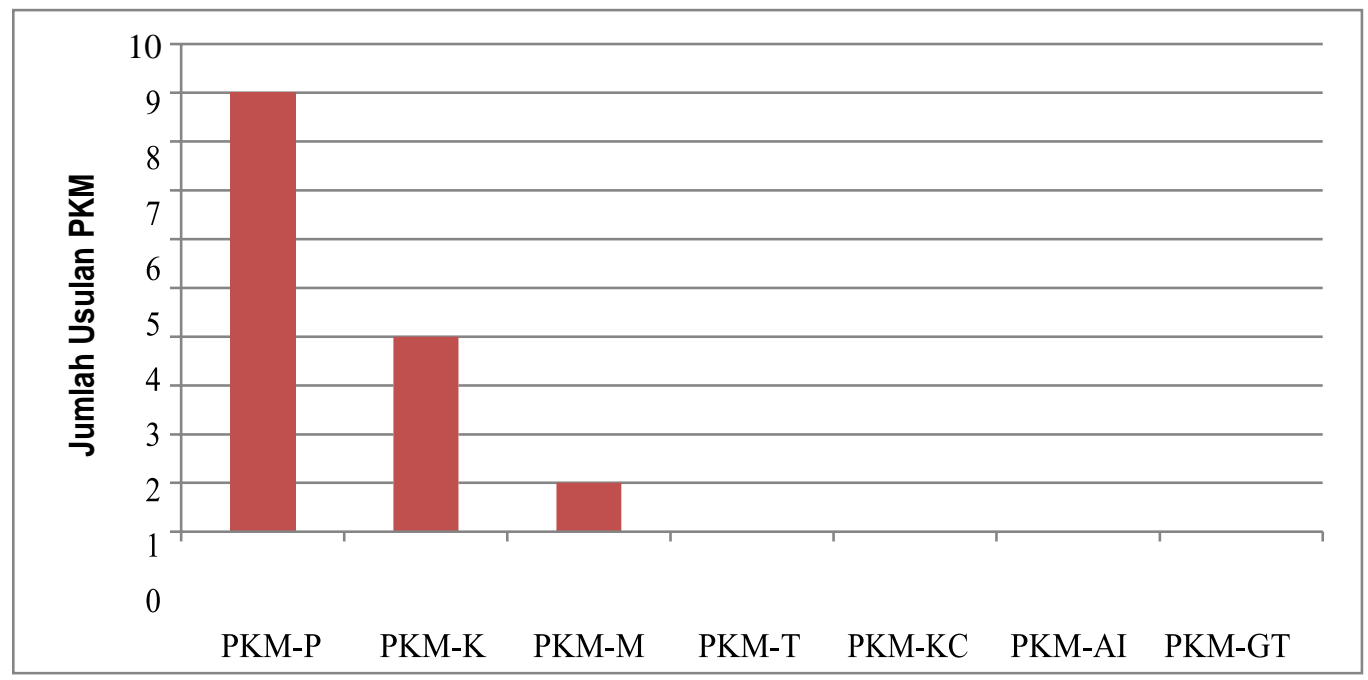

Gambar 4. Rekapitulasi Usulan PKM dari FT (tahun 2017 pendanaan 2018)

\section{Pembahasan}

Setelah melalui kegiatan IbM ini mahasiswa sudah bisa memahami masing masing kriteria 7 skim usulan PKM. Minat mahasiswa FT masih dominan skim PKM Penelitian. Jumlah usulan skim PKM-P yang diajukan sebesar 64,29\%, sedangkan jumlah usulan skim PKM-K yang diajukan sebesar 28,57\% sementara jumlah usulan skim PKM-M hanya 7,14\%. Untuk 4 skim usulan PKM lainnya yaitu PKM-T, PKM-AI dan PKM-GT masih 0\%. Hal ini memberikan gambaran bahwa menulis belum menjadi idola bagi mahasiswa di Fakultas Teknik, sehingga kedepannya hal ini perlu menjadi perhatian bersama untuk meningkatkan minat mahasiswa FT dalam membuat karya tulis/artikel ilmiah, salah satunya bisa melalui penguatan mata kuliah yang relevan ataupun metode pembelajaran berbasis output karya tulis mahasiswa. 


\section{KESIMPULAN}

Dari semua tahapan kegiatan pengabdian yang dilakukan maka dapat diambil kesimpulan sebagai berikut :

1. Minat mahasiswa FT masih dominan skim PKM-P yaitu sebesar $64,29 \%$, sedangkan jumlah usulan skim PKM-K yang diajukan sebesar 28,57\% sementara jumlah usulan skim PKM-M hanya $7,14 \%$.

2. Luaran yang dicapai dari kegiatan $\mathrm{IbM}$ ini adalah selain jasa pemberdayaan juga menghasilkan output kegiatan berupa proposal/usulan PKM tahun 2017 untuk pendanaan tahun 2018 sebanyak 14 usulan untuk 3 skim PKM.

\section{SARAN}

Dari semua data yang diperoleh maka dirasa perlu memperhatikan beberapa hal sebagai berikut :

1. Mengembangkan metode pembelajaran yang menarik minat dan bakat mahasiswa untuk lebih berkarya

2. Mengembangkan metode pembelajaran dengan kunjungan lapangan atau field trip untuk meningkatkan wawasan mahasiswa terhadap lingkungan sekitar.

3. Perlu peran strategis semua dosen khususnya dosen pendamping agar kegiatan PKM ini bisa maksimal dan sesuai dengan harapan bersama.

\section{DAFTAR PUSTAKA}

[1] Budi. D.A, Soeaidy. M.S, Hadi.M, Implementasi Program Pemberdayaan Masyarakat Melalui Pelatihan Keterampilan Dasar (Studi Di Kecamatan Tambaksari Kota Surabaya), Jurnal Administrasi Publik (JAP), Vol. 1, No. 5, Hal. 862-871

[2] Departemen Pekerjaan Umum Dirjen Cipta Karya, 2011, Strategi Pengembangan Kapasitas, PNPM Mandiri Perkotaan

[3] Purwanto. S, Suprakarti, Syrdayati.S, 2015, Pelatihan Pengembangan Media Pembelajaran Interaktif Berbasis Microsoft Power Point Untuk Peningkatan Kompetensi Guru Matematika Di MGMP Kecamatan Pulogadung, Jurnal Sarwahita, vol. 12 no. 1, 29-34

[4] Putri, L. D., lubis, fadrizal, \& Soehardi, F. (2017, September 4). Kolaborasi Perguruan Tinggi Dalam Perencanaan Teknis Infrastruktur Permukiman Bagi Masyarakat di Kecamatan Marpoyan Damai Kota Pekanbaru. http://doi.org/10.17605/OSF.IO/UN3G2

[5] Putri, L. D. (2017, September 4). KOLABORASI PERGURUAN TINGGI DALAM MENINGKATKAN PEMBERDAYAAN MASYARAKAT DI KOTA PEKANBARU. Retrieved from osf.io/thp9k

[6] Retnomurti. A.B, Nurhayati, Hendrawaty. N, 2016, Pelatihan Teknik Penulisan Surat Lamaran Pekerjaan Dan Daftar Riwayat Hidup Berbahasa Inggris Guru SMK Muhammadiyah 04 Slipi, Jurnal Kaji Tindak: Jurnal Pemberdayaan Masyarakat, Vol. 3 No. 2 Oktober 2016, 150-164

[7] Suarsa.P.W, Sutajaya.I.M, 2015, Pemberdayaan Masyarakat Melalui Pelatihan ErgoEntrepreneurship Untuk Mengembangkan Pengetahuan Dan Sikap Kewirausahaan Serta Meningkatkan Pendapatan Pedagang Kuliner Lokal Di Desa Peliatan, Ubud, Gianyar, Jurnal Ilmu Sosial dan Humaniora, vol. 4 no. 2, 609- 622 
[8] Suliyanthini.D, 2015, Pemberdayaan Ibu-Ibu Di Desa Pasauran Kecamatan Cinangka Provinsi Banten Dalam Mengisi Kegiatan PKK Membuat Produk Kerajinan Yang Berdaya Jual, Jurnal Sarwahita, vol. 12 no. 1, 53-57

[9] Tarma, Nurlaila.AM, Mulyati, 2015, Pelatihan Pembuatan Permen dan Jelly Antanan Sebagai Suplemen untuk Meningkatkan Kemampuan Daya Ingat Bagi Santri Penghafal AlQuran di Pesantren Sabila Citeureup Bogor, Jurnal Sarwahita, vol. 12 no. 1, 67-73

[10] Wiganda. S, 2015, Pelatihan Pembuatan Artikel Ilmiah Bagi Guru Guru Smk Se-Jakarta Pusat, Jurnal Sarwahita, vol. 12 no. 1, 35-43 